\title{
UTR-CTOE: A New Paradigm Explaining CAATs Adoption
}

\author{
Mootooganagen Ramen, Bhavish Jugurnath \\ University of Mauritius, Moka, Mauritius \\ Prachitee Ramhit \\ Barclays Bank, Mauritius
}

\begin{abstract}
Computer assisted audit techniques (CAATs) are audit technologies that allow auditors to perform their audit work efficiently and effectively. However, little is known about CAATs adoption process by audit firms. Therefore, this paper adapts the technology readiness theory (TRI), the unified theory of acceptance and use of technology (UTAUT) and the technology-organization environment (TOE) framework and Denison organizational culture theory, and presents a new theory of unified technology readiness and cultural-technological-organizational-environmental model (UTR-CTOE), to explain CAATs adoption at both individual level and firm level. The methodology used in the study consists of a random sampling among the auditors through the administration of questionnaire. A total of 581 auditors registered with Mauritius Institute of Professional Accountants (MIPA) respond to the survey. Our main findings of this paper confirm that the relation between beliefs, such as perceived usefulness, perceived ease of use, facilitating condition and social influence, and motivation is positively correlated, while beliefs have a negative correlation with inhibition towards CAATs adoption. Results also indicate that firm's decision for CAATs adoption is positively influenced by cultural, technological, organizational, and environmental factors. Furthermore, there is an indirect impact of firm's internal and external influences on auditors' adoption of CAATs.
\end{abstract}

Keywords: computer assisted audit techniques (CAATs), technology acceptance, culture, audit firm, unified technology readiness and cultural-technological-organizational-environmental model (UTR-CTOE)

\section{Introduction}

Information technology acceptance research portrays many competing models, with different sets of acceptance determinants. One of the most mature research areas in the information systems literature is that of explaining auditor acceptance of technology. Research, in this area, results in several theoretical models, which roots in psychology, information systems, and sociology that routinely explain over $40 \%$ of the variance in individual intention to use technology, namely, the innovations diffusion theory (IDT), social cognitive theory (SCT), theory of reasoned action (TRA), theory of planned behavior (TPB), technology acceptance model (TAM), combined TAM and TPB (C-TAM-TPB), motivational model (MM), model of PC utilization (MPCU), the technology readiness theory (TRI), the unified theory of acceptance and use of technology (UTAUT), and the technology-organization environment (TOE) theory. Many audit organizations choose to use information technologies for developing and improving their business work. This increases the need for computer assisted audit techniques (CAATs) to allow auditors to be able to perform their review and monitor tasks effectively, as well as, to play key roles in the process of innovation in those businesses more generally.

Mootooganagen Ramen, lecturer, Faculty of Law and Management, University of Mauritius.

Bhavish Jugurnath, lecturer, Faculty of Law and Management, University of Mauritius.

Prachitee Ramhit, analyst, Barclays Bank. 


\section{Problem Background}

Nowadays, as many businesses at present use IT to process their transactions, the auditing profession is faced with a need to give increased guidance for audits conducted in an IT environment. Various authoritative bodies, such as the American Institute of Certified Public Accountants (AICPA), the International Federation of Accountants (IFAC), and the Information Systems Audit and Control Association (ISACA) have issued standards in this area. Today's reality requires organizations to engage in the process of adopting technology to perform better in line with the challenges of globalization. The use of CAATs has been introduced to aid auditors in this regard (ISACA, 2010).

Many studies are made about the effectiveness of CAATs in the audit process and the applications of CAATs by both internal and external auditors. Most IS researchers study why and how individuals adopt new information technologies, explaining the factors influencing auditors to adopt IT by using intention or usage as a dependent variable whereby many theories and models are developed to explain CAATs adoption. These streams make important and unique contributions to the literature on user acceptance of IT. Eight famous models are analyzed and tested in almost all CAATs adoption researches, and recently, other models such as the UTAUT and TRI models are developed. However, current research in this field is fragmented. Besides, although most of the models developed consider various social factors, there is a lack of focus on organizational culture as a factor towards CAATs adoption as well as TRI model is excluded as a model to explain auditors' behavior towards CAATs. In addition to that, most of the studies on CAATs were conducted in the developed countries settings. Therefore, it is motivating to investigate CAATs adoption factors in the Mauritian context and to develop a new model that integrates UTAUT, TRI, TOE frameworks, and cultural theory.

\section{Research Objectives}

Researchers are confronted with a choice among a multitude of models. They find that they must "pick and choose" constructs across the models, or choose a "favored model". In so doing, they largely ignore the contributions from alternative models. Therefore, this paper has one overall objective, which is to develop a new model based on existing technology acceptance models, by considering cultural factors, and assess the validity of the generalized model among auditors in Mauritius.

\section{Significance of the Study}

The current study is significant as the fast progression of IT results in higher requirement of CAATs for auditing. Essentially, auditors will use CAATs for various reasons. Moreover, to better plan and prepare themselves for all the challenges that today's competing environment is bringing to them, this study investigates the determinants of CAATs adoption and provides recommendations to help audit firms to better understand the factors affecting IT adoption. In this way, audit firms can leverage on factors that increase adoption. This paper, therefore, seeks to develop a new model based on UTAUT, TRI, and TOE. But unlike existing models, the organizational cultural aspect is also considered as an additional construct and hence a new framework to guide auditors' behavior towards CAATs is proposed.

\section{Contribution of the Study}

This research particularly targets the audit profession fields by exploring technology adoption. By combining TRI, TOE, and Denison's culture models to the UTAUT, this study contributes to generating a comprehensive model that could better explain auditors' behavior towards CAATs adoption and guide future adoption of CAATTs by auditors in Mauritius. This research also contributes to the existing literature of technology adoption with the development of a new inclusive paradigm of UTR-CTOE in studying CAATs adoption. 


\section{Literature Review}

\section{Definition of CAATs}

CAATs are computer tools that extract and analyze data to assist auditors in the completion of an audit (Braun \& Davis, 2003). CAATs are computer programs and data that auditors use as part of the audit procedures to process data of audit significance, and which allow auditors to develop new ways to achieve the general audit objectives (Kamesam, 2001; Sayana, 2003). Similarly, Debreceny, Lee, Noe, and Toh (2005) stated that CAATs help auditors to assess the financial statement assertions, such as validity, completeness, ownership, valuation, accuracy, classification, and disclosure.

\section{Benefits of CAATs}

Different benefits of CAATs are highlighted in different research studies. According to Banker, Chang, and Kao (2002), Braun and Davis (2003), and Zhao, Yen, and Chang (2004), CAATs improve audit productivity, efficiency, effectiveness and complete routine tasks faster. CAAT is also regarded as a cost effective tool to conduct audit assignment (Saygili, 2010). Moreover, AICPA (2001), Singleton (2006), and Curtis and Payne (2008) stated that CAATs reduce total audit hours and increase the reliability of conclusions for test performed. CAATs also help auditors in the process of giving reasonable assurance (Vuchnich, 2008). Adopting CAATs in the audit profession certainly enhances competitiveness, efficiency, and effectiveness of audit services (IFAC, 2011).

\section{International Standards and Regulation of CAATs Adoption in Auditing}

Having regards to the benefits of CAATs, various regulatory bodies have issued standards integrating CAATs to assist in the planning, execution, and conclusion of an audit (Yang \& Guan, 2004; AICPA, 2001; 2002; 2005; 2009). Regulatory bodies include AICPA, International Auditing and Assurance Standards Board (IAASB), IFAC, ISACA, and Accounting Principle Board (APB). Many auditing standards, both US and UK, have been developed and implemented to ensure the effective use of CAATs worldwide (Ahmi \& Kent, 2013).

\section{Adoption of CAATs Worldwide}

Several countries have adopted CAATs, for instance, Australia uses CAATs audit databases to record audit. Belgium, Denmark, Hungary, Malaysia, Switzerland, and USA use CAATs to gather, analyze data and do sampling. Canada uses CAATs to analyze and do sampling, risk-based audit planning, audit procedures, and management of interview notes. India uses CAATs for data extraction and analysis. Korea uses general audit software to compare electronic accounting records with the related accounts of Bank of Korea for verification and doing risk analysis of the IS security. UK uses CAATs for documentation and data analysis. South Africa uses CAATs for security parameters evaluation and audit planning and working papers (International Organization of Supreme Audit Institutions [INTOSAI], 2013).

\section{Background of CAATs Adoption in Mauritius}

Reetun (2010) conducted a survey in Mauritius and found that CAATs, most specifically generalized audit software (GAS) such as interactive data extraction and analysis (IDEA), are used. One of the reasons why Mauritians use IDEA is that it meets the expectation of clients who invest heavily in technology and want the auditors to use it. It also increases efficiency and productivity, gains time by automating manual tasks, performs data analysis effectively, and offers value-added services. Williams (2012) reported that Mauritian auditors prefer computer tools than manual methods. This is illustrated by the figures of $63 \%$ stating that they would look to employ CAATs, 55\% implementing electronic working papers, 54\% implementing a real-time audit process, and $52 \%$ looking to focus on data mining over the next five years. 


\section{Theoretical Framework to Investigate Internal and External Factors of CAATs Adoption}

UTAUT model. Proposed by Venkatesh, Morris, G. B. Davis, and F. D. Davis (2003), this model integrates elements across eight models (i.e.: the IDT developed by Rogers, 1995; SCT proposed by Bandura, 1986; TRA by Fishbein \& Ajzen, 1975; TPB by Ajzen, 1991; TAM developed by Davis, 1989; C-TAM-TPB proposed by Taylor \& Todd, 1995; MM by Davis, Bagozzi, \& Warshaw, 1992; and MPCU proposed by Thompson, Higgins, \& Howell, 1991), to evaluate user intention on CAATs. As per literature, TRA, TAM, TPB, MM, C-TAM-TPB, MPCU, IDT, and SCT explain between $17 \%$ and $53 \%$ of the variance in user intention to use CAATs, while the UTAUT explains $70 \%$ of behavior intention and usage (Venkatesh et al., 2003).

Venkatesh et al. (2003) stated that behavioral intention to use a technology by individuals is influenced directly by the following four constructs:

(1) Performance expectancy or perceived usefulness: The belief of an individual that using technology tools will help him or her to attain significant rewards in job performance;

(2) Effort expectancy or perceived ease of use: The degree of ease associated with use of the tool, for example, auditors may be more at ease after a significant IT training;

(3) Social influence or perceived social influence: This refers to an individual's belief about the value that others believe he or she should use the innovation;

(4) Facilitating conditions or perceived facilitations: This refers to the belief that organizational and technical infrastructure exists to support use of the system.

TOE theory. Proposed by Tornatzky and Fleischer (1990), TOE framework describes how technology adoption occurs at firm level. TOE is a general theory of technology diffusion and effectively studies IS innovation adoption (Zhu, Kraemer, \& Xu, 2003; Venkatesh \& Bala, 2012). For this research, TOE model is applied as it addresses the technology adoption at firm level. Its independent variables are:

(1) Technological context: This refers to the relevant internal and external technology characteristics, such as assessing the cost-benefit of the technology, technology-task fit and risk;

(2) Organizational context: This refers to organization measures such as firm size, the centralization and complexity of managerial structure of top management;

(3) Environment context: This refers to the entities that exist in the industry such as suppliers, customers, competitors, regulatory agencies, stockholders, and other external pressures.

TRI theory or TR model. Proposed by Parasuraman (2000), TRI measures the personality traits of individuals. TR refers to people's propensity to adopt new technologies. The TR theory takes into account not only technical skills, but also people's feelings about technology. The constructs of TRI are:

(1) Optimism: Refers to the degree to which individuals believe that technology will increase control, flexibility, and efficiency in life;

(2) Innovativeness: Refers to the application of knowledge and leadership skill which positively influences technology readiness;

(3) Discomfort: A feeling of lack of control over technology which makes users reluctant to use technology;

(4) Insecurity: Doubts about technology's ability to work properly which negatively affect readiness.

Culture theory. According to Denison and Mishra (1995), culture theory comprises a range of complex social phenomena and involves the beliefs and assumptions that represent the deepest levels of organizational culture. 
Definition of culture. Culture is a way of life and affects everything people do (Ferraro, 2008). For example, psychologists discover that culture shapes judgment, memory, perception, and decision-making (Middleton, 2002). Culture also influences IT adoption (Krumbholz, Galliers, Coulianos, \& Maiden, 2000; Peterson, Miranda, Smith, \& Haskell, 2003). Because technology is frequently used in cultural contexts, culture can be said to be an element for CAATs adoption (Sun \& Zhang, 2006). Organizational culture has its major roots in culture theory.

Denison's organizational culture model. Denison and Mishra (1995) developed a typology of cultural attributes that impact firm's performance. The Denison model is based on four cultural traits of effective organizations:

(1) Involvement: This refers to a sense of ownership and responsibility among a firm's managers and employees who are committed to their work;

(2) Consistency: This refers to firms that have "strong" cultures that are highly consistent, well coordinated, and well integrated;

(3) Adaptability: This refers to the ability of a firm to adopt internal change in response to external conditions;

(4) Mission: This refers to a clear sense of purpose and direction that defines organizational goals and objectives.

\section{Moderators of CAATs Acceptance Models}

Age. Age refers to the age of the particular users which is measured by years. Scholars (Morris \& Venkatesh, 2000; Venkatesh et al., 2003) find evidence that explains the significant, direct, and moderating effect of age on behavioral intentions, adoption, and usage behaviors.

Gender. Gender refers to sexual categories of the CAATs users who are either male or female. Previous studies show that gender has a significant impact when considering technology and usage in organizational context. Venkatesh et al. (2003) found that the effect of perceived usefulness on behavioral intentions was moderated by gender.

Experience. Experience refers to the number of years within the service of the audit firm. Prior experience is an important determinant of behavior (Ajzen \& Fishbein, 1980). Evidence shows that the prior experience of the employees with any existing system can help them easily get used to newer similar systems in the organization (Kuan \& Chau, 2001; Dholakia \& Kshetri, 2004). For this study, IT experience of auditors is considered.

Voluntariness. This refers to the extent to which the use of the technology is perceived to be of free will (Venkatesh \& Davis, 2000). Voluntary use encourages a person's will to perform the behavior; in contrast, mandatory use hinders a person's will not to perform the behavior (Venkatesh \& Davis, 2000).

\section{Proposed Conceptual IT Acceptance Model}

In this study, the UTAUT model is modified and enriched by incorporating TRI and TOE, whereby TOE is enriched by incorporating culture as an additional construct. This permits the conceptualization of a single model to be applied by audit firms as depicted in Figure 1. 


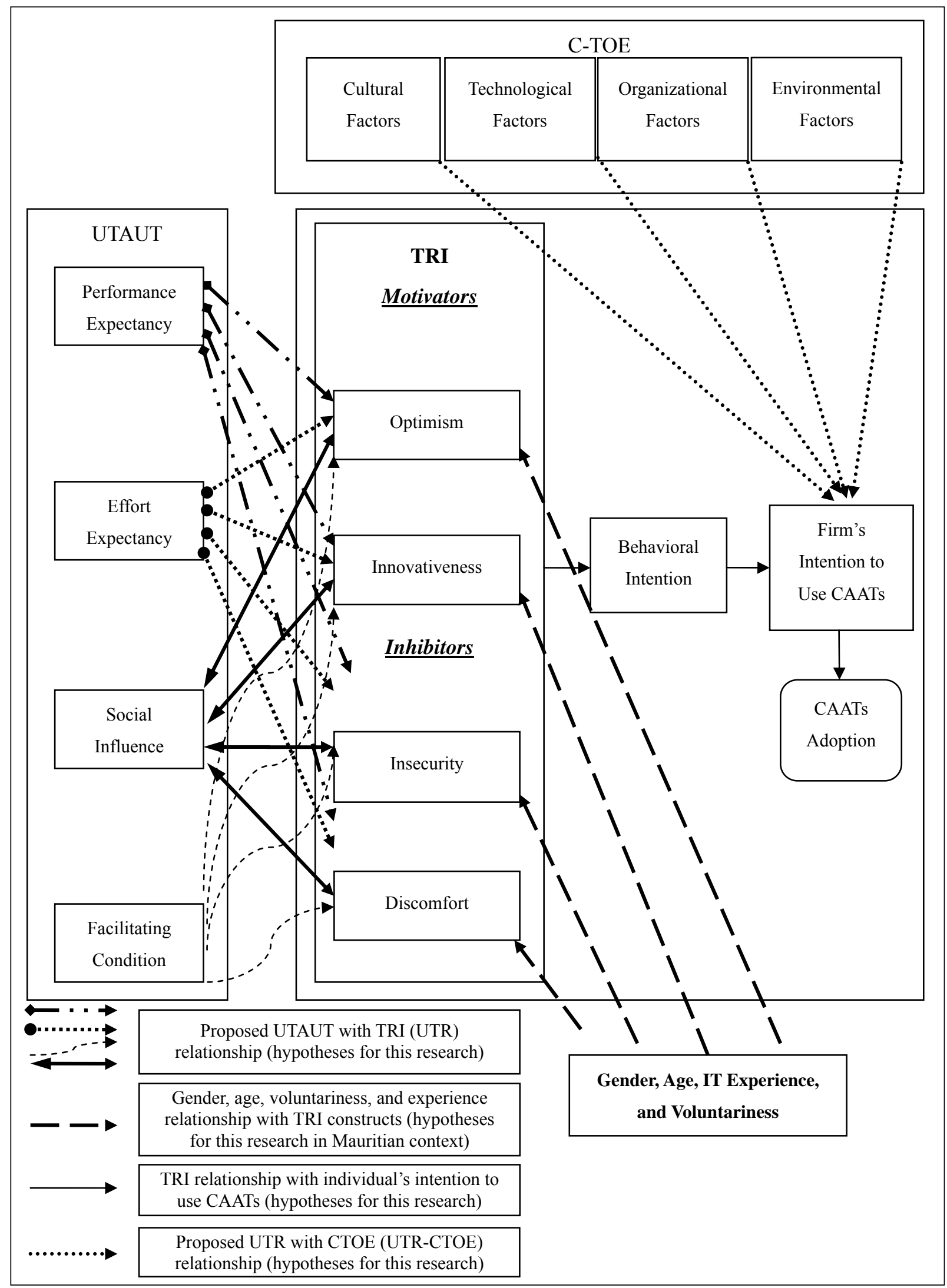

Figure 1. Proposed theoretical model of CAATs adoption by auditors (UTR-CTOE). 
In the context of the present study, the above hypotheses are derived in relation to the literature review on the new paradigm for explaining CAATs adoption. Cultural construct is combined with the theory of TOE model as they both measure IT adoption at firm's level. The dependent variable for this study is the adoption of CAATs. CAATs adoption is defined as the intention to use CAATs at both individual and firm levels. Here, the hypothesis is that beliefs affect personality dimensions which in turn influence behavior.

\section{Conclusion}

In conclusion, this literature helps to examine a new paradigm explaining CAATs adoption and then to test the hypothesis with new relationships formed in the new model. This research focuses on a new concept to guide audit firms to implement CAATs, and also adds a new model to other research in accounting and IT fields.

\section{Research Methodology}

Both quantitative research and qualitative research are adopted in the study. The methodology used in the study consists of a random sampling. Data are collected from secondary sources such as articles published by the well-known periodicals, books, and dissertations in order to base the construction of the theoretical framework. Primary sources via a questionnaire are also used. The population that is considered for this study is auditors from accounting and auditing firms registered with the Mauritius Institute of Professional Accountants (MIPA) in Mauritius ${ }^{1}$. A total of 133 companies are included in the sample. Questionnaires are distributed to the companies to be filled by the auditors.

\section{Results and Discussion}

The survey consists of participants from both rural and urban areas. Therefore, variations on the perceptions of auditors working in different firms are obtained, such that the characteristics of the different firms and individual auditors are analyzed.

This study produces results which corroborate the findings of a great deal of the previous work in this field. The research model projects that, beliefs (performance expectancy, effort expectancy, social influence and facilitating conditions) are positively associated with optimism and innovativeness traits. As per the correlation results from Table 1, the projected statements are true as it shows a significant correlation of $0.360,0.573,0.212$, and 0.201 respectively with optimism, and a significant correlation of $0.393,0.592,0.256$, and 0.264 respectively with innovativeness. These results indicate that, the more auditors believe CAATs will help them achieve improvements in their job performance, or CAATs are easy to use, or that facilitating conditions are available, the more motivated and confident they are to adopt CAATs. These results are to some extent in compliance with Venkatesh et al. (2003) who indicated that high perceived performance, ease of use, facilitation, and social influences increase technology adoption. Alternatively, the research also projects that, poor beliefs about CAATs lead to a high level of discomfort and insecurity. These results are in some way in compliance with Venkatesh et al. (2003), who reported that poor performance, effort expectancies, social influence, and facilitation results restraint CAATs adoption.

\footnotetext{
${ }^{1}$ Retrieved from http://www.mipa.mu/Files/MF-Members-List-2013.pdf.
} 
Table 1

Correlation Between Beliefs and Personality Traits

\begin{tabular}{llcccc}
\hline Predictor & & $\mathrm{OP}^{5}$ & $\mathrm{INV}^{6}$ & $\mathrm{DI}^{7}$ & $\mathrm{IS}^{8}$ \\
\hline \multirow{2}{*}{$\mathrm{PE}^{1}$} & Pearson correlation & $0.360^{* *}$ & $0.393^{* *}$ & $-0.349^{* *}$ & $-0.294^{* *}$ \\
& Sig. (2-tailed) & 0.000 & 0.000 & 0.000 & 0.000 \\
\hline \multirow{3}{*}{$\mathrm{EE}^{2}$} & $N$ & 581 & 581 & 581 & 581 \\
& Pearson correlation & $0.573^{* *}$ & $0.592^{* *}$ & $-0.598^{* *}$ & $-0.481^{* *}$ \\
& Sig. (2-tailed) & 0.000 & 0.000 & 0.000 & 0.000 \\
\hline \multirow{3}{*}{$\mathrm{SI}^{3}$} & $N$ & 581 & 581 & 581 & 581 \\
& Pearson correlation & $0.212^{* *}$ & $0.256^{* *}$ & $-0.225^{* *}$ & $-0.196^{* *}$ \\
& Sig. (2-tailed) & 0.000 & 0.000 & 0.000 & 0.000 \\
$\mathrm{FC}^{4}$ & $N$ & 581 & 581 & 581 & 581 \\
& Pearson correlation & $0.201^{* *}$ & $0.264^{* *}$ & $-0.189^{* *}$ & $-0.152^{* *}$ \\
& Sig. (2-tailed) & 0.000 & 0.000 & 0.000 & 0.000 \\
\hline
\end{tabular}

Notes. ${ }^{* *}:$ Correlation is significant at the 0.01 level (2-tailed). ${ }^{1}: \mathrm{PE}=$ Sum of performance expectancy questions 5 (range of 4-20, higher values indicate greater perceived performance); ${ }^{2}: \mathrm{EE}=$ Sum of effort expectancy questions 6 (range of 4-20, higher values indicate lower perceived effort or higher ease of use) $;^{3}: \mathrm{SI}=$ Sum of social influence questions 7 (range of 4-20, higher values indicate greater perceived social influence); ${ }^{4}: \mathrm{FC}=$ Sum of facilitating conditions questions 8 (range of $3-15$, higher values indicate greater perceived facilitation); ${ }^{5}$ : OP $=$ Sum of optimism questions 9 (range of 4-20, higher values indicate greater optimism); ${ }^{6}: \mathrm{INV}=$ Sum of innovativeness questions 10 (range of 4-20, higher values indicate greater innovativeness); 7: DI = Sum of discomfort questions 11 (range of 4-20, higher values indicate greater discomfort); ${ }^{8}:$ IS $=$ Sum of insecurity questions 12 (range of 4-20, higher values indicate greater insecurity).

Table 2

Regression Results for Motivation and Inhibition

\begin{tabular}{|c|c|c|c|c|c|}
\hline \multirow{2}{*}{ Dependent variable } & & \multicolumn{4}{|c|}{ Predictor } \\
\hline & & $\mathrm{PE}$ & $\mathrm{EE}$ & SI & $\mathrm{FC}$ \\
\hline \multirow{3}{*}{ OP } & Beta coefficient & -0.142 & 0.692 & -0.081 & 0.087 \\
\hline & $t$-value & -2.772 & 13.423 & -1.961 & 2.295 \\
\hline & $p$-value ${ }^{*}$ & 0.006 & 0.000 & 0.049 & 0.022 \\
\hline \multirow{3}{*}{ INV } & Beta coefficient & -0.111 & 0.665 & -0.062 & 0.140 \\
\hline & $t$-value & -2.204 & 13.147 & -1.541 & 3.778 \\
\hline & $p$-value ${ }^{*}$ & 0.028 & 0.000 & 0.124 & 0.000 \\
\hline \multirow{3}{*}{ DI } & Beta coefficient & 0.208 & -0.763 & 0.061 & -0.064 \\
\hline & $t$-value & 4.182 & -15.203 & 1.508 & -1.746 \\
\hline & $p$-value ${ }^{*}$ & 0.000 & 0.000 & 0.132 & 0.081 \\
\hline \multirow{3}{*}{ IS } & Beta coefficient & 0.141 & -0.589 & 0.031 & -0.043 \\
\hline & $t$-value & 2.569 & -10.609 & 0.690 & -1.060 \\
\hline & $p$-value ${ }^{*}$ & 0.010 & 0.000 & 0.490 & 0.290 \\
\hline
\end{tabular}

Note. : : Significant for variable with directional hypotheses (PE, EE, SI, FC) are depicted as 2-tailed.

Based on the results shown in Table 2, obtained from regression analysis, PE is quite a strong predictor of $\mathrm{OP}$, INV, DI, and IS $(p<0.05)$. Also, EE is a very strong predictor of OP, INV, DI, and IS $(p=0.000)$. SI is not significant $(p>0.05)$. FC is a significant predictor of OP $(p=0.022)$ and INV $(p=0.000)$, but is not a significant predictor of inhibition variables (as measured by DI $(p=0.081)$ and IS $(p=0.290)$ ). Among the predictor variables, EE tends to be the best predictor of OP $(t=13.423)$ and INV $(t=13.147)$, and is a strong predictor of the four personality traits, with OP, INV, DI, and IS $(p=0.000)$. One possible explanation is that, if technological tools need to be adopted and used, they first need to be user friendly and easy to use. Even if 
such technology is perceived to bring higher rewards, such as improving job performance, its ease of use is considered first. When individuals perceive high ease of use about a technology, then they are motivated to use such tools; whereas given a complex technology, which requires high effort, the individuals are inhibited from adopting such tools (Parasuraman, 2000). Developing training programs to use CAATs increases CAATs usage (Janvrin, Bierstaker, \& Lowe, 2008).

Table 3

Correlation Among Personality Traits and Auditors' Intention to Adopt CAATs

\begin{tabular}{|c|c|c|c|c|c|c|}
\hline \multirow{2}{*}{ Variable } & & \multicolumn{2}{|c|}{ Motivation } & \multicolumn{2}{|c|}{ Inhibition } & \multirow{2}{*}{$\begin{array}{l}\text { Individual intention } \\
\text { IBI }\end{array}$} \\
\hline & & $\mathrm{OP}$ & INV & $\mathrm{DI}$ & IS & \\
\hline & Pearson correlation & 1 & $0.819^{* *}$ & $-0.776^{* *}$ & $-0.722^{* *}$ & $0.348^{* *}$ \\
\hline \multirow[t]{3}{*}{$\mathrm{OP}$} & Sig. (2-tailed) & & 0.000 & 0.000 & 0.000 & 0.000 \\
\hline & $N$ & 581 & 581 & 581 & 581 & 581 \\
\hline & Pearson correlation & $0.819^{* *}$ & 1 & $-0.768^{* *}$ & $-0.688^{* *}$ & $0.332^{* *}$ \\
\hline \multirow[t]{3}{*}{ INV } & Sig. (2-tailed) & 0.000 & & 0.000 & 0.000 & 0.000 \\
\hline & $N$ & 581 & 581 & 581 & 581 & 581 \\
\hline & Pearson correlation & $-0.776^{* *}$ & $-0.768^{* *}$ & 1 & $0.731^{* *}$ & $-0.431^{* *}$ \\
\hline \multirow[t]{3}{*}{ DI } & Sig. (2-tailed) & 0.000 & 0.000 & & 0.000 & 0.000 \\
\hline & $N$ & 581 & 581 & 581 & 581 & 581 \\
\hline & Pearson correlation & $-0.722^{* *}$ & $-0.688^{* *}$ & $0.731^{* *}$ & 1 & $-0.322^{* *}$ \\
\hline \multirow[t]{3}{*}{ IS } & Sig. (2-tailed) & 0.000 & 0.000 & 0.000 & & 0.000 \\
\hline & $N$ & 581 & 581 & 581 & 581 & 581 \\
\hline & Pearson correlation & $0.348^{* *}$ & $0.332^{* *}$ & $-0.431^{* *}$ & $-0.322^{* *}$ & 1 \\
\hline \multirow[t]{2}{*}{ IBI $^{1}$} & Sig. (2-tailed) & 0.000 & 0.000 & 0.000 & 0.000 & \\
\hline & $N$ & 581 & 581 & 581 & 581 & 581 \\
\hline
\end{tabular}

Notes. ${ }^{* *}$ : Correlation is significant at the 0.01 level (2-tailed). ${ }^{1}:$ IBI $=$ Sum of behavioral intention questions 13 (range of 3-15, higher values indicate individual auditor's greater intention to adopt CAATs).

The findings of the current study also reveal that all the personality dimensions of TRI influence CAATs acceptance as shown in Table 3. There is a statistically significant positive association between motivation traits and behavioral intention. In addition, a statistically significant negative relationship exists between inhibition and individual's behavior towards CAATs adoption $(p=0.000)$. The negative relationships between inhibition traits and CAATs acceptance imply that, when auditors feel a lack of control over technology and feel insecure, they reject CAATs usage. One possible explanation is that auditors perceive high security and privacy threat, which restraint them from using technology. These findings are consistent with those of Parasuramen (2000), Jong, Ruyter, and Lemmink (2003), and Ward, Chitty, and Graham (2007).

Table 4

Statistics on Motivation and Inhibition Level for Male and Female

\begin{tabular}{llllll}
\hline & $\begin{array}{l}\text { Gender of } \\
\text { respondents }\end{array}$ & $N$ & Mean & Std. deviation & Std. error mean \\
\hline \multirow{2}{*}{ Motivation $^{1}$} & Female & 249 & 30.2209 & 4.38236 & 0.27772 \\
& Male & 332 & 34.6988 & 5.23291 & 0.28719 \\
\hline \multirow{2}{*}{ Inhibition $^{2}$} & Female & 249 & 19.9116 & 4.80845 & 0.30472 \\
& Male & 332 & 16.0331 & 5.16514 & 0.28347 \\
\hline
\end{tabular}

Note. ${ }^{\text {: }}$ Motivation $=$ Sum of OP and INV questions 9 and 10 (range of 8-40, higher values indicate greater motivation);

${ }^{2}:$ Inhibition $=$ Sum of DI and IS questions 11 and 12 (range of 8-40, higher values indicate greater inhibition). 
Table 5

Comparison on the Level of Motivation and Inhibition Between Gender

\begin{tabular}{|c|c|c|c|c|c|c|}
\hline & & \multicolumn{2}{|c|}{ Levene's test for equality of variances } & \multicolumn{3}{|c|}{$t$-test for equality of means } \\
\hline & & $F$ & Sig. & $t$ & df & Sig. (2-tailed) \\
\hline \multirow{2}{*}{ Motivation } & Equal variances assumed & 28.375 & 0.000 & -10.930 & 579 & 0.000 \\
\hline & Equal variances not assumed & & & -11.208 & 571.957 & 0.000 \\
\hline \multirow{2}{*}{ Inhibition } & Equal variances assumed & 13.146 & 0.000 & 9.224 & 579 & 0.000 \\
\hline & Equal variances not assumed & & & 9.319 & 552.788 & 0.000 \\
\hline
\end{tabular}

Given results of prior tests of technological acceptance, it is not surprising that individual characteristics influence personality traits towards CAATs adoption. An independent-samples $t$-test was conducted to compare the motivation and inhibition scores for male and female as shown in Table 5. The finding reveals that male participants are statistically significantly more likely to be motivated $(\mathrm{M}=34.6988, \mathrm{SD}=5.23291)$ as compared to female participants $(\mathrm{M}=30.2209$, $\mathrm{SD}=4.38236)$ (see Table 4). In order to know about the magnitude of the differences between the groups, eta squared is calculated. The magnitude of the differences in the means is very large (eta squared $=0.178$ ). Females are more inhibited towards CAATs adoption which can be explained by the fact that males tend to perceive higher ease of use and perceive usefulness of CAATs. This implies that males have higher beliefs than females, thus supporting the results of Venkatesh et al. (2003).

Table 6

ANOVA Test for Comparison of the Level of Motivation and Inhibition Among Different Age Groups

\begin{tabular}{lrrrrl}
\hline & Sum of squares & \multicolumn{1}{c}{ df } & Mean square & $F$ & Sig. \\
\hline \multirow{3}{*}{ Motivation } & 738.203 & 2 & 369.102 & 13.383 & 0.000 \\
& $15,941.597$ & 578 & 27.581 & & \\
\hline \multirow{4}{*}{ Inhibition } & $16,679.800$ & 580 & & & 0.000 \\
& 939.836 & 2 & 469.918 & 17.229 & \\
\hline
\end{tabular}

Table 7

Comparison on Motivation and Inhibition Scores Among Different Age Groups (Multiple Comparisons)

\begin{tabular}{|c|c|c|c|c|c|}
\hline \multicolumn{6}{|l|}{ Games-Howell } \\
\hline Dependent variable & $\begin{array}{l}\text { (I) Age of } \\
\text { respondents }\end{array}$ & $\begin{array}{l}\text { (J) Age of } \\
\text { respondents }\end{array}$ & $\begin{array}{l}\text { Mean difference } \\
(I-J)\end{array}$ & Std. error & Sig. \\
\hline \multirow{6}{*}{ Sum of motivation } & \multirow{2}{*}{$18-29$} & $30-44$ & $-2.40235^{*}$ & 0.48063 & 0.000 \\
\hline & & 45 years up & -1.05870 & 0.74640 & 0.334 \\
\hline & \multirow{2}{*}{$30-44$} & $18-29$ & $2.40235^{*}$ & 0.48063 & 0.000 \\
\hline & & 45 years up & 1.34365 & 0.66766 & 0.115 \\
\hline & \multirow{2}{*}{45 years up } & $18-29$ & 1.05870 & 0.74640 & 0.334 \\
\hline & & $30-44$ & -1.34365 & 0.66766 & 0.115 \\
\hline \multirow{6}{*}{ Sum of inhibition } & \multirow{2}{*}{$18-29$} & $30-44$ & $2.71241^{*}$ & 0.48168 & 0.000 \\
\hline & & 45 years up & 1.66502 & 0.72818 & 0.061 \\
\hline & \multirow{2}{*}{$30-44$} & $18-29$ & $-2.71241^{*}$ & 0.48168 & 0.000 \\
\hline & & 45 years up & -1.04739 & 0.63956 & 0.235 \\
\hline & \multirow{2}{*}{45 years up } & $18-29$ & -1.66502 & 0.72818 & 0.061 \\
\hline & & $30-44$ & 1.04739 & 0.63956 & 0.235 \\
\hline
\end{tabular}

Note. : The mean difference is significant at the 0.05 level. 
A one-way between-group analysis (ANOVA) was carried out to explore the impact of age on the level of motivation, as well as, on the level of inhibition. Subjects are divided into three groups according to their age (Group 1: 18-29; Group 2: 30-44; and Group 3: $\geq 45$ ), as shown in Table 6. There is a statistically significant difference at $p<0.05$ level in the motivation scores for the three age groups $(F(2,578)=13.383, p=0.000)$, and also in the inhibition scores $(F(2,578)=17.229, p=0.000)$. Post-hoc comparisons using the Games-Howell test were conducted (see Table 7). Surprisingly, no significant differences are found between elder auditors, who are 45 years old or above, and young auditors $(<30$ years old), as well as, between elder auditors and middle-aged auditors $(<44$ years old, $p>0.005)$. Contrary to expectations, middle-aged auditors are more likely to be motivated, while younger ones are more inhibited to adopt CAATs. This result is consistent with that of Venkatesh et al. (2003) who found that intention to adopt technology is stronger for older workers. One explanation is that, younger auditors, especially those new to the field, may fear of not being able to use the technology tool properly or lack of confidence towards CAATs. They may fear of making mistakes during audit process while using technological audit tools, which they have never used until they started working.

However, these above results about gender and age deviate from that found by Curtis and Payne (2008), who reported that neither gender nor age is significantly related to CAATs adoption.

Table 8

Mean Motivation and Inhibition Scores for Auditors With Different IT Experience

\begin{tabular}{llrlllll}
\hline & & $N$ & Mean & Std. deviation & Std. error & Minimum & Maximum \\
\hline \multirow{5}{*}{ Motivation } & Low experience & 47 & 21.8511 & 7.32470 & 1.06842 & 12.00 & 35.00 \\
& Moderate experience & 242 & 32.9793 & 3.69866 & 0.23776 & 18.00 & 40.00 \\
& High experience & 292 & 34.3733 & 3.95434 & 0.23141 & 26.00 & 40.00 \\
& Total & 581 & 32.7797 & 5.36267 & 0.22248 & 12.00 & 40.00 \\
\hline \multirow{5}{*}{ Inhibition } & Low experience & 47 & 28.9149 & 7.27064 & 1.06053 & 16.00 & 38.00 \\
& Moderate experience & 242 & 17.8512 & 3.88135 & 0.24950 & 9.00 & 28.00 \\
& High experience & 292 & 15.7603 & 3.53053 & 0.20661 & 9.00 & 25.00 \\
& Total & 581 & 17.6954 & 5.36674 & 0.22265 & 9.00 & 38.00 \\
\hline
\end{tabular}

Table 9

Comparison of Motivation and Inhibition Scores Depending on IT Skills (Multiple Comparisons)

\begin{tabular}{|c|c|c|c|c|c|c|c|}
\hline \multicolumn{8}{|c|}{ Games-Howell } \\
\hline \multirow{2}{*}{$\begin{array}{l}\text { Dependent } \\
\text { variable }\end{array}$} & \multirow{2}{*}{$\begin{array}{l}\text { (I) What is your } \\
\text { self-assessment about } \\
\text { using technology? }\end{array}$} & \multirow{2}{*}{$\begin{array}{l}\text { (J) What is your } \\
\text { self-assessment about } \\
\text { using technology? }\end{array}$} & \multirow{2}{*}{$\begin{array}{l}\text { Mean } \\
\text { difference } \\
(\mathrm{I}-\mathrm{J})\end{array}$} & \multirow[b]{2}{*}{ Std. error } & \multirow[b]{2}{*}{ Sig. } & \multicolumn{2}{|c|}{$95 \%$ confidence interval } \\
\hline & & & & & & $\begin{array}{l}\text { Lower } \\
\text { bound }\end{array}$ & $\begin{array}{l}\text { Upper } \\
\text { bound }\end{array}$ \\
\hline \multirow{6}{*}{ Motivation } & \multirow{2}{*}{ Low experience } & Moderate experience & $-11.12828^{*}$ & 0.67339 & 0.000 & -13.7711 & -8.4855 \\
\hline & & High experience & $-12.52222^{*}$ & 0.66395 & 0.000 & -15.1621 & -9.8823 \\
\hline & \multirow{2}{*}{ Moderate experience } & Low experience & $11.12828^{*}$ & 0.67339 & 0.000 & 8.4855 & 13.7711 \\
\hline & & High experience & $-1.39395^{*}$ & 0.36724 & 0.000 & -2.1738 & -0.6141 \\
\hline & \multirow{2}{*}{ High experience } & Low experience & $12.52222^{*}$ & 0.66395 & 0.000 & 9.8823 & 15.1621 \\
\hline & & Moderate experience & $1.39395^{*}$ & 0.36724 & 0.000 & 0.6141 & 2.1738 \\
\hline \multirow{6}{*}{ Inhibition } & \multirow{2}{*}{ Low experience } & Moderate experience & $11.06365^{*}$ & 0.65265 & 0.000 & 8.4340 & 13.6933 \\
\hline & & High experience & $13.15462^{*}$ & 0.64350 & 0.000 & 10.5441 & 15.7651 \\
\hline & \multirow{2}{*}{ Moderate experience } & Low experience & $-11.06365^{*}$ & 0.65265 & 0.000 & -13.6933 & -8.4340 \\
\hline & & High experience & $2.09097^{*}$ & 0.35593 & 0.000 & 1.3294 & 2.8525 \\
\hline & \multirow{2}{*}{ High experience } & Low experience & $-13.15462^{*}$ & 0.64350 & 0.000 & -15.7651 & -10.5441 \\
\hline & & Moderate experience & $-2.09097^{*}$ & 0.35593 & 0.000 & -2.8525 & -1.3294 \\
\hline
\end{tabular}

Note. : The mean difference is significant at the 0.05 level. 
Results also show that respondents with high IT experience are more likely to be motivated to adopt CAATs than those having low IT experience (see Table 8). Post-hoc comparisons using the Games-Howell test (see Table 9) reveal the mean motivation score for the three groups; low experienced $(\mathrm{M}=21.8511$, $\mathrm{SD}=7.32470)$, moderate experienced $(\mathrm{M}=32.9793, \mathrm{SD}=3.69866)$, and high experienced $(\mathrm{M}=34.3733$, $\mathrm{SD}=3.95434)$ significantly differ. Auditors with low IT experience are more likely to be inhibited $(\mathrm{M}=28.9149, \mathrm{SD}=7.27064)$ than those having moderate $\mathrm{IT}$ experience $(\mathrm{M}=17.8512, \mathrm{SD}=3.88135)$ and high experience $(M=15.7603, S D=3.53053)$. This result supports those of Kuan and Chau $(2001)$ and Dholakia and Kshetri (2004), who reported that prior experience of the employees with any existing system helps them easily get used to newer similar systems in the organization. This explains the reason why high IT experienced auditors are more motivated towards CAATs adoption. It can be concluded that there is a direct relationship between age and IT experience, as supported by Venkatesh et al. (2003).

Table 10

Comparison on the Level of Motivation and Inhibition Based on Voluntary and Mandatory Use of CAATs (T-Test)

\begin{tabular}{|c|c|c|c|c|c|c|}
\hline & & \multicolumn{2}{|c|}{ Levene's test for equality of variances } & \multicolumn{3}{|c|}{$t$-test for equality of means } \\
\hline & & $F$ & Sig. & $t$ & $\mathrm{df}$ & Sig. (2-tailed) \\
\hline Motivation & Equal variances assumed & 2.758 & 0.097 & -1.873 & 579 & 0.062 \\
\hline Motivation & Equal variances not assumed & & & -3.587 & 12.907 & 0.003 \\
\hline Inhibition & $\begin{array}{l}\text { Equal variances assumed } \\
\text { Equal variances not assumed }\end{array}$ & 1.267 & 0.261 & $\begin{array}{l}2.658 \\
4.325\end{array}$ & $\begin{array}{l}579 \\
12.326\end{array}$ & $\begin{array}{l}0.008 \\
0.001\end{array}$ \\
\hline
\end{tabular}

The study posits that, when individuals use CAATs voluntarily, they are more motivated than when they use it mandatorily. An independent-samples $t$-test was used as shown in Table 10. No statistically significant differences between voluntary use of CAATs and mandatory use of CAATs are found in the case of motivation $(p>0.005)$. On the other hand, surprisingly, there is a statistically significant difference between voluntary CAATs usage and mandatory use of CAATs when respondents are inhibited to adopt CAATs $(p=0.000)$. Auditors are less inhibited when they are given directive to use CAATs, thus contradicting Venkatesh et al.'s (2003) finding. One reason for this is that, when auditors are given the choice of using CAATs by their own free will, rather than be given directive by the departmental manager, they tend to be less confident to use CAATs, as there is no visible support from management towards the use of CAATs.

It is found that CAATs adoption varies by firm size. This is consistent with Zhu et al.'s (2003) findings. As shown in Table 11, respondents assign higher mean ratings to cultural traits (4.10), technological factors (4.34), and organizational factors (4.24) than to environmental factors (3.93). This implies that cultural traits exist within firms to influence their CAATs adoption decisions. Organizational factors, such as resources and management commitment, exist to permit firms' CAATs adoption. Technological factors are also taken into account when implementing CAATs. These three factors mostly influence CAATs adoption. However, environmental attributes are close to 4.00. These reflect that most respondents tend to agree that environmental factors do exist within their firms to influence their firms' decisions as well. Results showed that all the four influences within small firms, middle-sized firms, and big firms differ significantly from each other $(p=0.000)$, and that cultural traits, technological, organizational, and environmental influences within audit firms increase the likelihood that audit firms will adopt CAATs. ANOVA using Games-Howell was carried out to explore the differences between the level of cultural traits, organizational, technological, and environmental influences that exist within the different firm sizes to adopt CAATs as shown in Table 12. Big firms have much more cultural traits within their organizations than small firms and middle ones. Small firms have lower cultural traits as 
compared to medium and big firms. More organizational influences exist within big and medium firms to affect their CAATs adoption than small ones. Lower levels of technological influences exist in small firms to affect the decision to adopt CAATs than big and middle firms. In addition, small firms tend to have a lower level of influence from external factors, to impact on their CAATs adoption. Thus, small firms take more time to adopt audit technology and tend to use less advanced audit technologies, than medium and big firms. Big audit firms tend to adopt more advanced CAAT tools in less time, such as within 12 months. This result is consistent with Ismail and Abidin's (2009) findings that many small firms use less advanced CAAT tools. It is found that higher cultural traits, organizational, technological, and environmental influences exist within big audit firms, such that they are more likely to be able to adopt CAATs, as compared to small and medium ones. Small firms do not experience a high level of cultural, organizational, technological, and environmental influences. This can explain the reason why they do not consider CAATs adoption so quickly. These small enterprises have accounting transaction volumes that are manageable to be audited manually and performed just by using basic auditing tools such as spreadsheets. Another reason can be that auditors in small firms are unclear about vendor services in giving adequate and quality trainings to staffs which is an important influence. Thus, IT vendors should communicate the benefits of IT products through promotional seminars and on-site visits (Iacovou, Benbasat, \& Dexter, 1995). By doing so, more audit firms will realize CAATs' advantages, thus increasing its adoption.

Table 11

Means of Variables Affecting Firm's Intention to Adopt CAATs $(N=581)$

\begin{tabular}{|c|c|c|}
\hline Variable affecting firm's intention to adopt CAATs & Mean $^{1}$ & Std. dev. \\
\hline Average cultural traits & 4.10 & 0.428 \\
\hline Most people in the company have input into decisions that affect them & 4.19 & 0.399 \\
\hline Cooperation and collaboration across functional roles are actively encouraged & 4.19 & 0.398 \\
\hline Approach to do business is very consistent and predictable & 4.11 & 0.529 \\
\hline There is a high level of agreement about the way business is done & 3.96 & 0.719 \\
\hline Our firm is very responsive and changes easily with fast changing environment & 3.88 & 0.996 \\
\hline Clients' comments and recommendations often lead to changes in our organization & 3.55 & 1.063 \\
\hline The company has a long-term purpose and direction & 4.41 & 0.499 \\
\hline There is a shared vision of what this company will be like in the future & 4.47 & 0.506 \\
\hline Average technological factors & 4.34 & 0.314 \\
\hline CAATs will reduce error rates in audit process & 4.32 & 0.466 \\
\hline CAATs will increase audit firm’s productivity & 4.26 & 0.441 \\
\hline Benefits of using CAATs outweigh its initial investment cost & 4.41 & 0.493 \\
\hline CAATs are compatible with our firm's work procedures & 4.48 & 0.524 \\
\hline CAATs will fit well with auditor's tasks in performing audits & 4.30 & 0.459 \\
\hline CAATs are compatible with our firm's current ways of doing audit procedures & 4.28 & 0.508 \\
\hline Average organizational factors & 4.24 & 0.302 \\
\hline Top management provides adequate financial resources for CAATs implementation & 3.99 & 0.619 \\
\hline Top management gives strong support for CAATs usage in firm's operation & 3.96 & 0.584 \\
\hline Top management is willing to take the risks involved in the adoption of CAATs & 4.08 & 0.513 \\
\hline Financial resources are available to permit our firm to implement CAATs & 4.25 & 0.468 \\
\hline Audit staffs are trained enough to use CAATs & 4.46 & 0.526 \\
\hline Organizational and technical infrastructure exists to support the use of CAATs & 4.32 & 0.511 \\
\hline Our employees have sufficient knowledge to use the result produced by CAATs & 4.34 & 0.476 \\
\hline Our employees know how to operate CAATs & 4.36 & 0.481 \\
\hline Our employees have the necessary technical, managerial, and other skills to implement CAATs & 4.39 & 0.499 \\
\hline
\end{tabular}


(Table 11 continued)

\begin{tabular}{lll}
\hline Variable affecting firm's intention to adopt CAATs & Mean $^{1}$ & Std. dev. \\
\hline Average environmental factors & 3.93 & 0.595 \\
\hline The majority of our clients have large accounting transaction volumes & 3.81 & 1.063 \\
The majority of our clients have complex financial reporting system & 3.79 & 1.136 \\
The majority of our clients have highly computerized financial reporting system & 3.79 & 1.135 \\
Our firm would have experienced a competitive disadvantage if CAATs had not been adopted & 4.15 & 0.521 \\
Our main competitors that have adopted CAATs have benefited greatly & 4.26 & 0.555 \\
Our firm's decision to implement CAATs is affected by competitors in the audit industry & 4.15 & 0.692 \\
CAATs vendor consults firm on CAATs benefits & 3.80 & 0.776 \\
CAATs vendor provides adequate trainings to staffs in audit firms to implement CAATs & 3.93 & 0.853 \\
CAATs vendor provides adequate technical support on CAATs usage & 3.69 & 0.818 \\
\hline
\end{tabular}

Note. $^{1}$ : Participants were asked to indicate the extent to which they agree from 1 (strongly disagree) to 5 (strongly agree) with each statement.

Table 12

Factors'Differences in Influencing CAATs Adoption

\begin{tabular}{|c|c|c|c|c|c|}
\hline Dependent variable & Organization size (I) & Organization size $(\mathrm{J})$ & Mean difference (I-J) & Std. error & Sig. \\
\hline \multirow{6}{*}{ Culture } & \multirow{2}{*}{ Small } & Middle & $-4.03673^{*}$ & 0.23584 & 0.000 \\
\hline & & Big & $-7.17407^{*}$ & 0.28349 & 0.000 \\
\hline & \multirow{2}{*}{ Middle } & Small & $4.03673^{*}$ & 0.23584 & 0.000 \\
\hline & & Big & $-3.13734^{*}$ & 0.20775 & 0.000 \\
\hline & \multirow{2}{*}{ Big } & Small & $7.17407^{*}$ & 0.28349 & 0.000 \\
\hline & & Middle & $3.13734^{*}$ & 0.20775 & 0.000 \\
\hline \multirow{6}{*}{ Organizational } & \multirow{2}{*}{ Small } & Middle & $-2.85833^{*}$ & 0.263 & 0.000 \\
\hline & & Big & $-3.25833^{*}$ & 0.29377 & 0.000 \\
\hline & \multirow{2}{*}{ Middle } & Small & $2.85833^{*}$ & 0.263 & 0.000 \\
\hline & & Big & -0.4 & 0.22735 & 0.185 \\
\hline & \multirow{2}{*}{ Big } & Small & $3.25833^{*}$ & 0.29377 & 0.000 \\
\hline & & Middle & 0.4 & 0.22735 & 0.185 \\
\hline \multirow{6}{*}{ Technological } & \multirow{2}{*}{ Small } & Middle & $-1.19694^{*}$ & 0.18107 & 0.000 \\
\hline & & Big & $-1.09537^{*}$ & 0.16905 & 0.000 \\
\hline & \multirow{2}{*}{ Middle } & Small & $1.19694^{*}$ & 0.18107 & 0.000 \\
\hline & & Big & 0.10157 & 0.17825 & 0.836 \\
\hline & \multirow{2}{*}{ Big } & Small & $1.09537^{*}$ & 0.16905 & 0.000 \\
\hline & & Middle & -0.10157 & 0.17825 & 0.836 \\
\hline \multirow{6}{*}{ Environmental } & \multirow{2}{*}{ Small } & Middle & $-8.38759^{*}$ & 0.53728 & 0.000 \\
\hline & & Big & $-9.76852^{*}$ & 0.53159 & 0.000 \\
\hline & \multirow{2}{*}{ Middle } & Small & $8.38759^{*}$ & 0.53728 & 0.000 \\
\hline & & Big & $-1.38093^{*}$ & 0.31379 & 0.000 \\
\hline & \multirow{2}{*}{ Big } & Small & $9.76852^{*}$ & 0.53159 & 0.000 \\
\hline & & Middle & $1.38093^{*}$ & 0.31379 & 0.000 \\
\hline
\end{tabular}

Note. : : The mean difference is significant at the 0.05 level.

Furthermore, analysis reveals that actual CAATs adoption by audit firms is directly affected by auditors' behavioral acceptance of CAATs $(r=0.450, p=0.000)$ (see Table 13 below). Cultural, organizational, technological, and environmental influences also impact firms' CAATs adoption. This indicates an indirect statistically significant positive influence of CTOE on auditors' adoption of CAATs $(r=0.412, p=0.000)$. This 
can be explained by the fact that, even if management wants to improve its auditors' productivity by adopting CAATs, the audit firm should also consider internal and external factors affecting it and if these factors favor auditors' CAATs adoption, such as resources.

Table 13

Correlation Between Individual Intention With CTOE Factor and With Firm's Intention to Adopt CAATs

\begin{tabular}{llccc}
\hline & & IBI & CTOE & \multicolumn{1}{c}{ FI } \\
\hline \multirow{2}{*}{ IBI $^{1}$} & Pearson correlation & 1 & $0.412^{* *}$ & $0.450^{* *}$ \\
& Sig. (2-tailed) & & 0.000 & 0.000 \\
& $N$ & 581 & 581 & 581 \\
FI $^{2}$ & Pearson correlation & $0.412^{* *}$ & 1 & 1 \\
& Sig. (2-tailed) & 0.000 & 581 & 581 \\
\hline
\end{tabular}

Notes. ${ }^{* *}$ : Correlation is significant at the 0.01 level (2-tailed). ' $:$ IBI = Sum of behavioral intention questions 13 (range of 3-15, higher values indicate individual auditor's greater intention to adopt CAATs); ${ }^{2}$ : FI = Sum of firm's intention questions 26 (range of 2-10, higher values indicate greater intention to adopt CAATs).

\section{Conclusion and Further Research}

This study presents the conceptual framework for CAATs adoption by auditors. The empirical quantitative data collected indicate a very positive relation between the proposed UTR-CTOE paradigm constructs and the dependent variable (intention to use CAATs). It is argued that the adoption of CAATs does not simply depend on individual auditor's acceptance but it is also subject to organizational, technological, and other environmental factors affecting the firm. It is further argued that culture plays a vital role in influencing auditors within the organization as a whole to adopt CAATs. The new paradigm, UTR-CTOE, provides a comprehensive context of individual, technological, cultural, organizational, and environmental influences to examine CAATs adoption by audit firms.

On one hand, the model explains that beliefs affect an individual auditor's personality dimensions. As such, UTR-CTOE provides a useful tool for auditors to help them understand the drivers of acceptance. On the other hand, the model also explains the reason why CAATs are rejected in organizations even where auditors are highly motivated in general. If firm's specific characteristics (i.e., financial resources, size, workforce's competency, culture traits) are poor, CAATs will be rejected regardless of auditors' general CAATs readiness. Hence, factors influencing a firm's decision should be considered, so as for necessary steps to be taken to initiate successful CAATs implementation.

In sum, a combination of four models in UTR-CTOE framework comprises a holistic view. It shows that CAATs adoption involves individuals' beliefs, their characteristics, as well as firms' characteristics and both internal and external influences. The model will benefit audit firms by providing a useful tool for auditors to help them understand the drivers of acceptance and to proactively plan intervention (including training).

This study considers only CAATs acceptance by Mauritian auditors. For future research, other countries can further apply the UTR-CTOE framework.

\section{References}

Ahmi, A., \& Kent, S. (2013). The utilisation of generalized audit software (GAS) by external auditors. Managerial Auditing Journal, 28(2), 88-113.

Ajzen, I. (1991). The theory of planned behavior. Organizational Behavior and Human Decision Processes, 50(2), $179-211$. 
Ajzen, I., \& Fishbein, M. (1980). Understanding attitudes and predicting social behavior. Englewood Cliffs, NJ: Prentice Hall. American Institute of Certified Public Accountants [AICPA]. (2001). The effect of information technology on the auditor's consideration of internal control in a financial statement audit. Statement of Auditing Standards No. 94. New York, NY: AICPA.

American Institute of Certified Public Accountants [AICPA]. (2002). Consideration of fraud in a financial statement audit. Statement of Auditing Standards No. 99. New York, NY: AICPA.

American Institute of Certified Public Accountants [AICPA]. (2005). Audit documentation. Statement of Auditing Standards No. 103. New York, NY: AICPA.

American Institute of Certified Public Accountants [AICPA]. (2009). Interim financial information. Statement of Auditing Standards No. 116. New York, NY: AICPA.

Bandura, A. (1986). Social foundation of thought and action: A social cognitive theory. Englewood Cliffs, NJ: Prentice Hall.

Banker, R. D., Chang, H., \& Kao, Y. (2002). Impact of information technology on public accounting firm productivity. Journal of Information Systems, 16(2), 209-222.

Braun, R. L., \& Davis, H. E. (2003). Computer-assisted audit tools and techniques: Analysis and perspectives. Managerial Auditing Journal, 18(9), 725-731.

Curtis, M. B., \& Payne, E. A. (2008). An examination of contextual factors and individual characteristics affecting technology implementation decisions in auditing. Internal Journal of Accounting Information Systems, 9(2), 104-121.

Davis, F. D. (1989). Perceived usefulness, perceived ease of use, and user acceptance of information technology. MIS Quarterly, 13(3), 319-340.

Davis, F. D., Bagozzi, R. P., \& Warshaw, P. R. (1992). Extrinsic and intrinsic motivation to use computers in the workplace. Journal of Applied Social Psychology, 22(14), 1111-1132.

Debreceny, R., Lee, S. L., Noe, W., \& Toh, J. S. (2005). Employing generalized audit software in the financial services sector: Challenges and opportunities. Managerial Auditing Journal, 20(6), 605-618.

Denison, D. R., \& Mishra, A. K. (1995). Toward a theory of organizational culture and effectiveness. Organization Science, 6(2), 204-223.

Dholakia, R. R., \& Kshetri, N. (2004). Factors impacting the adoption of the internet among SMEs. Small Business Economics, 23(4), 311-322.

Ferraro, G. (2008). Cultural anthropology: An applied perspective. Belmont, CA: Thomson/Wadsworth.

Fishbein, M., \& Ajzen, I. (1975). Belief, attitude, intention, and behavior: An introduction to theory and research. Reading, MA: Addison-Wesley.

Iacovou, C. L., Benbasat, I., \& Dexter, A. S. (1995). Electronic data interchange and small organizations: Adoption and impact of technology. MIS Quarterly, 19(4), 465-485.

International Federation of Accountants [IFAC]. (2011). Technology and e-business (Module 5). In Guide to practice management for small- and medium-sized practices (2nd ed.). International Federation of Accountants.

International Organization of Supreme Audit Institutions [INTOSAI]. (2013). Software for different types of audits. Retrieved from http://intosaiitaudit.org/directory/topic/Soft2.htm

Information Systems Audit and Control Association [ISACA]. (2010). IT standards, guidelines, and tools and techniques for audit and assurance and control professionals. ISACA. Retrieved from http://www.isaca.org/knowledge-center/Standards/Documents/ALL-IT-Standards-Guidelines-and-Tools.pdf

Ismail, N. A., \& Abidin, A. Z. (2009). Perception towards the importance and knowledge of information technology among auditors in Malaysia. Journal of Accounting and Taxation, 1(4), 61-69.

Janvrin, D., Bierstaker, J., \& Lowe, D. J. (2008). An examination of audit information technology use and perceived importance. Accounting Horizons, 22(1), 1-21.

Jong, A., Ruyter, K., \& Lemmink, J. (2003). The adoption of information technology by self-managing service teams. Journal of Service Research, 6(2), 162-179.

Kamesam, V. (2001). Information systems auditing policy for the banking and financial sector. Department of Information Technology, Reserve Bank of India, Mumbai. Retrieved from http://www.rbi.org.in/scripts/PublicationReportDetails.aspx?UrlPage=\&ID=275

Krumbholz, M., Galliers, J., Coulianos, N., \& Maiden, N. A. M. (2000). Implementing enterprise resource planning packages in different corporate and national cultures. Journal of Information Technology, 15(4), 267-279.

Kuan, K. K. Y., \& Chau, P. Y. K. (2001). A perception-based model for EDI adoption in small businesses using a technology-organization-environment framework. Information \& Management, 38(8), 507-521. 
Middleton, D. (2002). Succession and change in the sociocultural use of memory: Building-in the past in communicative action. Culture \& Psychology, 8(1), 79-95.

Morris, M. G., \& Venkatesh, V. (2000). Age differences in technology adoption decisions: Implications for a changing work force. Personnel Psychology, 53(2), 375-403.

Parasuraman, A. (2000). Technology readiness index (TRI): A multiple-item scale to measure readiness to embrace new technologies. Journal of Service Research, 2(4), 307-320.

Peterson, M. F., Miranda, S. M., Smith, P. B., \& Haskell, V. M. (2003). The sociocultural contexts of decision making in organizations. In S. L. Schneider, \& J. Shanteau (Eds.), Emerging perspectives on judgment and decision research (pp. 512-555). Cambridge, UK: Cambridge University Press.

Reetun, K. (2010). Tri-annual scientific competition 2011: The use of information technology in the audit process. Mauritius: National Audit Office.

Rogers, E. M. (1995). Diffusion of innovations (4th ed.). New York, NY: Free Press.

Sayana, S. A. (2003). Using CAATs to support IS audit. Information Systems Control Journal, Vol. 1.

Saygili, A. T. (2010). Taking advantage of computer assisted audit tools and techniques during testing phase in financial audits: An empirical study in a food processing company in Turkey. Global Journal of Management and Business Research, 10(2), 113-119.

Singleton, T. (2006). Generalized audit software: Effective and efficient tool for today's IT audits. Information Systems Control Journal, 2, 1-3.

Sun, H., \& Zhang, P. (2006). The role of moderating factors in user technology acceptance. International Journal of Human-Computer Studies, 64(2), 53-78.

Taylor, S., \& Todd, P. (1995). Assessing IT usage: The role of prior experience. MIS Quarterly, 19(4), 561-570.

Thompson, R. L., Higgins, C. A., \& Howell, J. M. (1991). Personal computing: Toward a conceptual model of utilization. MIS Quarterly, 15(1), 125-143.

Tornatzky, L., \& Fleischer, M. (1990). The processes of technological innovation. Lexington, MA: Lexington Books.

Venkatesh, V., \& Bala, H. (2012). Adoption and impacts of interorganizational business process standards: Role of partnering synergy. Information Systems Research, 23(4), 1131-1157.

Venkatesh, V., \& Davis, F. D. (2000). A theoretical extension of the technology acceptance model: Four longitudinal field studies. Management Science, 46(2), 186-204.

Venkatesh, V., Morris, M. G., Davis, G. B., \& Davis, F. D. (2003). User acceptance of information technology: Toward a unified view. MIS Quarterly, 27(3), 425-478.

Vuchnich, A. (2008). Using CAATTs in preliminary analytical review to enhance the auditor's risk assessment. CPA Journal, $78(5), 38-41$.

Ward, S., Chitty, B., \& Graham, G. (2007). Finding the tutorial I want: An examination of factors leading to the adoption of online self service technology. Proceedings of the ANZMAC Conference 2007 (pp. 2580-2587), New Zealand.

Williams, S. (2012). The changing face of internal audit. Shirley Williams Communications. Retrieved from http://www.insurancegateway.co.za/LifeProfessionals/PressRoom/ViewPress/Irn=5964\&URL=The+changing + face + of + Inter nal+Audit

Yang, D. C., \& Guan, L. (2004). The evolution of IT auditing and internal control standards in financial statement audits: The case of the United States. Managerial Auditing Journal, 19(4), 544-555.

Zhao, N., Yen, D. C., \& Chang, I. (2004). Auditing in the e-commerce era. Information Management \& Computer Security, 12(5), 389-400.

Zhu, K., Kraemer, K., \& Xu, S. (2003). Electronic business adoption by European firms: A cross-country assessment of the facilitators and inhibitors. European Journal of Information Systems, 12(4), 251-268. 